\title{
Consenso iberoamericano para uniformar la nomenclatura de la función y las enfermedades renales
}

\author{
Ibero-American consensus to standardize the nomenclature of kidney function and \\ diseases: a proposal from the SLANH
}

\begin{abstract}
Alejandro Ferreiro-Fuentes ${ }^{1}, M^{a}$ Carlota González-Bedat ${ }^{1,2}$, Raúl, Lombardi ${ }^{1,3}$, Jocemir Lugon ${ }^{4}$, Gianna Mastroianni ${ }^{4}$, Filipe Mira ${ }^{5}$, Guillermo Rosa-Diez ${ }^{1,2 *}$, José E. Sánchez ${ }^{6}$ y José Suassuna ${ }^{4}$
\end{abstract}

${ }^{1}$ Sociedad Latinoamericana de Nefrología e Hipertensión (SLANH), Montevideo, Argentina; ${ }^{2}$ Registro Latinoamericano de Diálisis y Trasplante, Uruguay; ${ }^{3}$ Comité de IRA de SLANH, Buenos Aires, Argentina; ${ }^{4}$ Sociedad Brasileña de Nefrología, Rio de Janeiro, Brasil; ${ }^{5}$ Sociedad Portuguesa de Nefrología, Coimbra, Portugal; ${ }^{6}$ Sociedad Española de Nefrología, Oviedo, España

A pesar del aumento de la carga mundial de la enfermedad renal, su conocimiento público aún es limitado, lo cual destaca la necesidad de establecer una comunicación efectiva de la salud renal con la comunidad de las partes interesadas. El mensaje debe ser claro; sin embargo, la nomenclatura utilizada hasta la fecha para describir la función y la enfermedad renal carece de uniformidad.

En junio de 2019, la fundación Kidney Disease: Improving Global Outcomes (KDIGO) convocó a una conferencia de consenso con el objetivo de estandarizar y depurar la nomenclatura empleada en idioma inglés para describir la función y enfermedad renales y desarrollar un glosario que pudiera utilizarse en publicaciones científicas. Los principios rectores de la conferencia establecieron que la nomenclatura revisada debía centrarse en el paciente y ser precisa y coherente con la nomenclatura empleada en las directrices de KDIGO. Los asistentes a la conferencia consideraron que la estandarización de la nomenclatura científica era esencial para mejorar la comunicación, alcanzaron un consenso general y redactaron las recomendaciones y el glosario publicado en fecha reciente ${ }^{1}$.

El Registro Latinoamericano de Diálisis y Trasplante Renal y el Comité de IRA de la Sociedad
Latinoamericana de Nefrología e Hipertensión (SLANH) consideraron necesaria una comunicación efectiva en la comunidad iberoamericana y ello llevó a trabajar en una versión iberoamericana de consenso con el objetivo de estandarizar, acordar y uniformar la nomenclatura usada a partir de entonces. La Sociedad Española de Nefrología (SEN), la Sociedad Brasileña de Nefrología (SBN) y la Sociedad Portuguesa de Nefrología (SPN) aceptaron la convocatoria y los resultados del trabajo del grupo sobre la nomenclatura en lengua española y portuguesa aparecen en las tablas 1 a 5 . Estas tablas, que se publican en el número actual de Nefrología Latinoamérica en español y portugués, aparecerán también en las revistas de los órganos oficiales de las sociedades respectivas.

La finalidad de SLANH y todas las sociedades participantes es conseguir la mayor difusión y establecer una comunicación efectiva para el cuidado de la salud renal.

\section{Bibliografía}

1. Levey AS, Eckardt KU, Dorman NM, Christiansen SL, Hoorn EJ, Ingelfinger JR, et al. Nomenclature for kidney function and disease: report of a kidney disease: Improving Global Outcomes (KDIGO) Consensus Conference. Kidney Int. 2020;97(6):1117-1129.

\footnotetext{
Correspondencia:

Fecha de recepción: 28-10-2020

Fecha de aceptación: 30-10-2020

DOI: 10.24875/NEFRO.M20000009

*Guillermo Rosa-Diez

E-mail: kavac7@gmail.com

2444-9032/@ 2020 Sociedad Latinoamericana de Nefrología e Hipertensión.

licencia CC BY-NC-ND (http://creativecommons.org/licenses/by-nc-nd/4.0/).

Disponible en internet: 17-12-2020 Nefro Latinoam. 2020;17:55-67 www.nefrologialatinoamericana.com es un artículo open access bajo la
} 
Nefro Latinoam. 2020;17

Tabla 1. Función y enfermedad renales

\begin{tabular}{|c|c|c|c|}
\hline Término preferido & $\begin{array}{l}\text { Abreviaturas } \\
\text { sugeridas }^{\mathrm{a}}\end{array}$ & Fundamento/explicación & Términos a evitar \\
\hline $\begin{array}{l}\text { Parte 1. Función y } \\
\text { enfermedad renales }\end{array}$ & & No aplica en español & No aplica en español \\
\hline Enfermedad renal & & $\begin{array}{l}\text { Refleja la totalidad de los trastornos, afecciones y } \\
\text { problemas renales agudos y crónicos }\end{array}$ & $\begin{array}{l}\text { Nefropatía (salvo } \\
\text { excepciones) }\end{array}$ \\
\hline Función renal & & $\begin{array}{l}\text { Refleja la totalidad de las complejas funciones } \\
\text { fisiológicas del riñón; no equivale exclusivamente a } \\
\text { la tasa de filtración glomerular (TFG) }\end{array}$ & No aplica en español \\
\hline Función renal normal & & $\begin{array}{l}\text { Término general aplicable a varios aspectos de la } \\
\text { función renal que deben especificarse }\end{array}$ & \\
\hline Alteración de la función renal & & $\begin{array}{l}\text { Término general aplicable a varios aspectos de la } \\
\text { función renal que deben especificarse }\end{array}$ & $\begin{array}{l}\text { Insuficiencia, disfunción } \\
\text { renal, azotemia }\end{array}$ \\
\hline Función renal residual & FRR & $\begin{array}{l}\text { Función renal en personas con falla renal en } \\
\text { tratamiento renal sustitutivo; se requieren } \\
\text { especificaciones, por ejemplo diuresis o depuración } \\
\text { de solutos. Aunque se usa por lo general en el } \\
\text { ámbito de la diálisis, este término también puede } \\
\text { emplearse para referirse a la función de los riñones } \\
\text { nativos en pacientes trasplantados }\end{array}$ & No aplica en español \\
\hline Estructura renal & & $\begin{array}{l}\text { Término general aplicable a varios aspectos de la } \\
\text { estructura renal, los cuales deben especificarse }\end{array}$ & \\
\hline Estructura renal normal & & $\begin{array}{l}\text { Término general aplicable a varios aspectos de la } \\
\text { estructura renal, los cuales deben especificarse }\end{array}$ & \\
\hline Causas de enfermedad renal & & $\begin{array}{l}\text { La causa de la enfermedad renal, aguda o crónica, } \\
\text { debe indicarse siempre que sea posible. La causa } \\
\text { puede ser conocida, presumible o desconocida. Se } \\
\text { debe especificar el método diagnóstico }\end{array}$ & $\begin{array}{l}\text { La causa no debe } \\
\text { inferirse a partir de una } \\
\text { anomalía comórbida } \\
\text { (p. ej., diabetes) }\end{array}$ \\
\hline
\end{tabular}

Tabla 2. Falla renal

\begin{tabular}{|c|c|c|c|}
\hline Término preferido & $\begin{array}{l}\text { Abreviaturas } \\
\text { sugeridas }^{\mathrm{a}}\end{array}$ & Fundamento/explicación & Términos a evitar \\
\hline Parte 2. Falla renal & & $\begin{array}{l}\mathrm{FG}<15 \mathrm{ml} / \mathrm{min} \text { por } 1.73 \mathrm{~m}^{2} \text { o en tratamiento } \\
\text { dialítico; se requiere mayor especificación, } \\
\text { véase más adelante }\end{array}$ & $\begin{array}{l}\text { Insuficiencia renal (IR); enfermedad renal } \\
\text { terminal (ERT); enfermedad renal; nefropatía, } \\
\text { insuficiencia, disfunción; azotemia }\end{array}$ \\
\hline Duración & & Es preferible proporcionar especificaciones & \\
\hline $\begin{array}{l}\text { Disfunción renal } \\
\text { aguda, estadio } 3^{\text {b }}\end{array}$ & $\begin{array}{l}\text { DRA estadio } \\
3\end{array}$ & Duración de la enfermedad $\leq 3$ meses & $\begin{array}{l}\text { Falla renal aguda; enfermedad renal; } \\
\text { insuficiencia renal, insuficiencia, disfunción; } \\
\text { azotemia; uremia }\end{array}$ \\
\hline Falla renal & FR & Duración de la enfermedad $>3$ meses & $\begin{array}{l}\text { Falla renal crónica; nefropatía crónica; } \\
\text { insuficiencia renal crónica, insuficiencia, } \\
\text { disfunción; azotemia; uremia; insuficiencia } \\
\text { renal irreversible }\end{array}$ \\
\hline Síntomas y signos & & $\begin{array}{l}\text { Es preferible proporcionar especificaciones } \\
\text { (con o sin síntomas y signos desconocidos); } \\
\text { con síntomas y signos podría ser sinónimo de } \\
\text { uremia }\end{array}$ & \\
\hline $\begin{array}{l}\text { Uremia/síndrome } \\
\text { urémico }\end{array}$ & & $\begin{array}{l}\text { Síndrome consistente en síntomas y signos } \\
\text { relacionados con falla renal (no indica que la } \\
\text { urea sea la causa) }\end{array}$ & \\
\hline
\end{tabular}


Tabla 2. Falla renal (Continuación)

\begin{tabular}{|c|c|c|c|}
\hline Término preferido & $\begin{array}{l}\text { Abreviaturas } \\
\text { sugeridas }^{\mathrm{a}}\end{array}$ & Fundamento/explicación & Términos a evitar \\
\hline Tratamiento & & Es preferible proporcionar especificaciones & \\
\hline $\begin{array}{l}\text { Tratamiento renal } \\
\text { de sustituciónc }\end{array}$ & TRS & $\begin{array}{l}\text { Es preferible proporcionar especificaciones, } \\
\text { incluidos diálisis o trasplante actuales }\end{array}$ & Tratamiento de reemplazo renal (TRR) \\
\hline \multirow[t]{2}{*}{ Diálisis } & $\begin{array}{l}\text { DRA, estadio } \\
\text { 3D }\end{array}$ & FRA, estadio 3 tratado con diálisis & DRA dependiente de diálisis \\
\hline & $\begin{array}{l}\text { ERC, estadio } \\
5 D\end{array}$ & ERC, estadio 5 tratado con diálisis & ERCT, ERC dependiente de diálisis \\
\hline Duración & & $\begin{array}{l}\text { Larga o corta duración: larga duración se } \\
\text { refiere a la diálisis como tratamiento de la } \\
\text { ERC; también puede referirse a diálisis de } \\
\text { mantenimiento. Corta indica la diálisis como } \\
\text { tratamiento de la DRA }\end{array}$ & $\begin{array}{l}\text { Diálisis crónica, diálisis aguda (los términos } \\
\text { agudo o crónico hacen referencia a la } \\
\text { duración de la enfermedad renal más que a } \\
\text { la duración del tratamiento con diálisis) }\end{array}$ \\
\hline $\begin{array}{l}\text { Modalidad y } \\
\text { frecuencia }\end{array}$ & & $\begin{array}{l}\text { Modalidades: } \\
\text { hemodiálisis (HD) } \\
\text { hemofiltración (HF) } \\
\text { hemodiafiltración (HDF) } \\
\text { diálisis peritoneal (DP, ambulatoria o } \\
\text { automática) } \\
\text { Frecuencia: } \\
\text { continua } \\
\text { intermitente (corta o prolongada) }\end{array}$ & \\
\hline Trasplante renal & $\begin{array}{l}\text { ERC, estadios } \\
1 \mathrm{~T}-5 \mathrm{~T}\end{array}$ & ERC, estadios G1-G5 después del trasplante & ERCT \\
\hline Origen del órgano & & $\begin{array}{l}\text { Debe especificarse si el riñón procede de un } \\
\text { donante vivo o cadavérico }\end{array}$ & \\
\hline $\begin{array}{l}\text { Falla renal con } \\
\text { tratamiento } \\
\text { sustitutivo de la } \\
\text { función renal }\end{array}$ & ERC con TRS & $\begin{array}{l}\text { ERC, estadio G5 tratada con diálisis, o ERC, } \\
\text { estadios G1-G5 luego de trasplante renal; } \\
\text { para estudios epidemiológicos se deben } \\
\text { incluir ambos }\end{array}$ & ERCT \\
\hline $\begin{array}{l}\text { Falla renal sin } \\
\text { tratamiento } \\
\text { sustitutivo de la } \\
\text { función renalzz }\end{array}$ & $\begin{array}{l}\text { ERC, estadio } \\
5 \text { sin TRS }\end{array}$ & $\begin{array}{l}\text { Es preferible proporcionar más explicaciones; } \\
\text { especificar si el TRS no es escogido o no } \\
\text { está disponible }\end{array}$ & ERCT, falla renal no tratada \\
\hline $\begin{array}{l}\text { Con tratamiento } \\
\text { conservador } \\
\text { integral }\end{array}$ & & $\begin{array}{l}\text { Es preferible proporcionar más explicaciones; } \\
\text { la definición está en evolución }\end{array}$ & \\
\hline $\begin{array}{l}\text { Sin tratamiento } \\
\text { conservador } \\
\text { integral }\end{array}$ & & $\begin{array}{l}\text { Es preferible proporcionar más explicaciones; } \\
\text { especificar si el tratamiento conservador no } \\
\text { es escogido o no está disponible }\end{array}$ & \\
\hline
\end{tabular}

Tabla 3. Enfermedad renal aguda (ERA) y Lesion Renal Aguda (LRA)

\begin{tabular}{|c|c|c|c|}
\hline Término preferido & $\begin{array}{l}\text { Abreviaciones } \\
\text { sugeridas }^{\mathrm{a}}\end{array}$ & Fundamento/explicación & Términos a evitar \\
\hline $\begin{array}{l}\text { Parte } 3 . \\
\text { Enfermedades y daño } \\
\text { renal agudos (DRA) }\end{array}$ & & $\begin{array}{l}\text { Duración de la enfermedad menor de } 3 \text { meses; se debe } \\
\text { diferenciar conceptualmente del reconocimiento } \\
\text { inicial de una ERC }\end{array}$ & $\begin{array}{l}\text { Falla renal aguda e } \\
\text { insuficiencia renal aguda }\end{array}$ \\
\hline $\begin{array}{l}\text { Enfermedad renal } \\
\text { aguda }\end{array}$ & ERA & $\begin{array}{l}\text { Definición KDIGO: IRA o TFG }<60 \mathrm{ml} / \mathrm{min} \text { por } 1.73 \mathrm{~m}^{2} \text {, o } \\
\text { marcadores de daño renal en } \leq 3 \mathrm{meses}, 0 \text { descenso de } \\
35 \% \text { de TFG o aumento de creatinina sérica de } 50 \% \text { en } \\
\leq 3\end{array}$ & IRA, FRA \\
\hline Lesión renal aguda & LRA & Definición KDIGO (la IRA es una subcategoría de ERA) & IRA, FRA \\
\hline
\end{tabular}


Tabla 3. Enfermedad renal aguda (ERA) y Lesion Renal Aguda (LRA) (Continuación)

\begin{tabular}{|c|c|c|c|}
\hline Término preferido & $\begin{array}{l}\text { Abreviaciones } \\
\text { sugeridas }^{a}\end{array}$ & Fundamento/explicación & Términos a evitar \\
\hline $\begin{array}{l}\text { Clasificación de la } \\
\text { LRA }\end{array}$ & & $\begin{array}{l}\text { Utilizar preferentemente clasificación por causa y } \\
\text { estadio, más que por estadio solo, por ejemplo paciente } \\
\text { con LRA, estadio } 3 \text { por necrosis tubular aguda. El } \\
\text { criterio se aplica a todos los estadios de LRA }\end{array}$ & $\begin{array}{l}\text { Clasificaciones previas, } \\
\text { incluidas RIFLE y AKIN } \\
\text { (concertadas por la } \\
\text { clasificación KDIGO) }\end{array}$ \\
\hline $\begin{array}{l}\text { Clasificación de la } \\
\text { LRA }\end{array}$ & & $\begin{array}{l}\text { Utilizar preferentemente clasificación por causa y } \\
\text { estadio, más que por estadio solo, por ejemplo paciente } \\
\text { con LRA, estadio } 3 \text { por necrosis tubular aguda. El } \\
\text { criterio se aplica a todos los estadios de LRA }\end{array}$ & $\begin{array}{l}\text { Clasificaciones previas, } \\
\text { incluidas RIFLE y AKIN } \\
\text { (concertadas por la } \\
\text { clasificación KDIGO) }\end{array}$ \\
\hline \multirow[t]{4}{*}{ Estadios de IRA } & & Definición KDIGO (aplicable sólo a pacientes con LRA) & \\
\hline & LRA, estadio 1 & Criterio basado en la creatinina sérica o diuresis & \\
\hline & LRA, estadio 2 & Criterio basado en la creatinina sérica o diuresis & \\
\hline & LRA, estadio 3 & Criterio basado en la creatinina sérica o diuresis & \\
\hline
\end{tabular}

Tabla 4. Enfermedad renal crónica

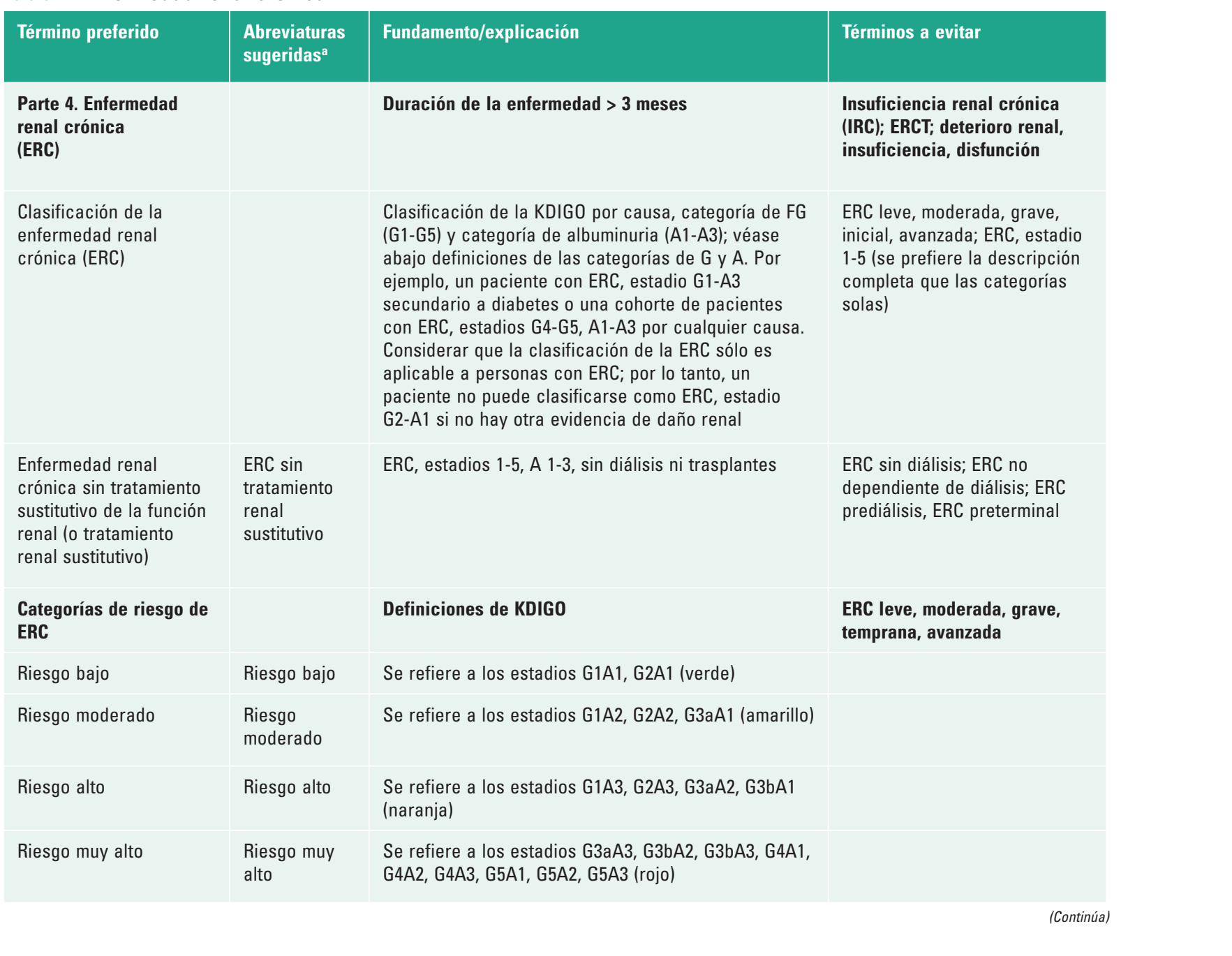


Tabla 4. Enfermedad renal crónica (Continuación)

\begin{tabular}{|l|l|l|l|l|l}
\hline Término preferido & $\begin{array}{l}\text { Abreviaturas } \\
\text { sugeridas }\end{array}$ & Fundamento/explicación & Términos a evitar \\
\hline $\begin{array}{l}\text { Avance de la } \\
\text { enfermedad renal } \\
\text { crónica (ERC) }\end{array}$ & $\begin{array}{l}\text { Se refiere al empeoramiento de la FG o albuminuria. } \\
\text { No se incluyen otros biomarcadores. Todavía no hay } \\
\text { consenso sobre el uso de términos específicos para } \\
\text { describir tiempos (p. ej., temprano, tardío) o grado } \\
\text { (rápido, lento) de avance. El uso de términos } \\
\text { específicos debe definirse en los métodos. Se } \\
\text { requieren mayores especificaciones. El descenso de } \\
\text { la FG puede ocurrir durante el tratamiento de otras } \\
\text { enfermedades, lo cual no debe considerarse como } \\
\text { avance de la ERC }\end{array}$ \\
\hline & $\begin{array}{l}\text { Es posible que se requiera una especificación } \\
\text { adicional: puede producirse una disminución de la }\end{array}$ \\
\hline & $\begin{array}{l}\text { TFG durante el tratamiento de otras afecciones, lo } \\
\text { que no puede considerarse un avance de la ERC }\end{array}$ \\
\hline $\begin{array}{l}\text { Remisión de la } \\
\text { enfermedad renal } \\
\text { crónica (ERC) }\end{array}$ & $\begin{array}{l}\text { Se refiere a la mejoría de la FG o albuminuria. Los } \\
\text { criterios dependen de la enfermedad. El uso de } \\
\text { términos específicos debe definirse en los métodos }\end{array}$ \\
\hline
\end{tabular}

Tabla 5. Indicadores de la función renal

\begin{tabular}{|c|c|c|c|}
\hline Término preferido & $\begin{array}{l}\text { Abreviaturas } \\
\text { sugeridas }^{\mathrm{a}}\end{array}$ & Fundamento/explicación & Términos a evitar \\
\hline $\begin{array}{l}\text { Parte } 5 \text {. Medidas de la } \\
\text { función renal }\end{array}$ & & Se aplica a personas con y sin enfermedad renal & $\begin{array}{l}\text { Indicadores de la } \\
\text { función renal }\end{array}$ \\
\hline $\begin{array}{l}\text { Filtración glomerular } 0 \\
\text { aclaramiento }\end{array}$ & & FG y aclaramiento de creatinina no son sinónimos & \\
\hline Filtración glomerular & FG & $\begin{array}{l}\text { Se deben especificar las unidades } \\
\text { (ml/min por } 1.73 \mathrm{~m}^{2} 0 \mathrm{ml} / \mathrm{min} \text { ) }\end{array}$ & \\
\hline $\begin{array}{l}\text { Filtración glomerular } \\
\text { medida }\end{array}$ & $\mathrm{FGm}$ & $\begin{array}{l}\text { Los métodos usados para el aclaramiento y los marcadores } \\
\text { deben especificarse de forma separada en los métodos }\end{array}$ & \\
\hline $\begin{array}{l}\text { Filtración glomerular } \\
\text { estimada }\end{array}$ & Fge & $\begin{array}{l}\text { Las fórmulas de estimación (p. ej., CKD-EPI y el estudio } \\
\text { MDRD) y los marcadores de filtración (p. ej., creatinina y } \\
\text { cistatina C) deben definirse de forma separada en los métodos }\end{array}$ & \\
\hline \multirow[t]{2}{*}{$\begin{array}{l}\text { Marcador de la filtración } \\
\text { glomerular estimada }\end{array}$} & $\mathrm{FG}_{\mathrm{cr}}$ & $\begin{array}{l}\text { Estimación de la FG con uso de creatinina o cistatina } \\
\text { Estimación de la FG con uso de creatinina y cistatina C }\end{array}$ & \\
\hline & $\begin{array}{l}\mathrm{FGe}_{\text {cys }} \\
\mathrm{FGe}_{\text {cr-cys }}\end{array}$ & & \\
\hline Aclaramiento & $\mathrm{Acl}$ & $\begin{array}{l}\text { Debe especificarse el soluto; deben especificarse las } \\
\text { unidades (ml/min por } 1.73 \mathrm{~m}^{2} 0 \mathrm{ml} / \mathrm{min} \text { ) }\end{array}$ & \\
\hline Aclaramiento medido & Aclm & $\begin{array}{l}\text { Los métodos usados para el aclaramiento y los marcadores } \\
\text { deben especificarse de forma separada en los métodos }\end{array}$ & \\
\hline $\begin{array}{l}\text { Marcador de } \\
\text { aclaramiento }\end{array}$ & $\begin{array}{l}\mathrm{ACIm}_{\mathrm{UN}} \\
\mathrm{ACIm} \\
{ }_{\mathrm{A}} \mathrm{Cl} \\
\mathrm{UN}-\mathrm{cr}\end{array}$ & $\begin{array}{l}\text { Marcador de aclaramiento con uso del nitrógeno ureico, } \\
\text { marcador de aclaramiento con uso de la creatinina }\end{array}$ & \\
\hline Aclaramiento estimado & Acle & $\begin{array}{l}\text { Las fórmulas de estimación (p. ej., Cockcroft-Gault) y los } \\
\text { marcadores deben definirse de forma separada en los } \\
\text { métodos }\end{array}$ & \\
\hline
\end{tabular}


Nefro Latinoam. 2020;17

Tabla 5. Indicadores de la función renal (Continuación)

Término preferido
$\begin{aligned} & \text { Marcador de } \\ & \text { aclaramiento estimado }\end{aligned}$
$\begin{aligned} & \text { Categorías de la filtración } \\ & \text { glomerular }\end{aligned}$

Normal a aumento de la filtración glomerular

Filtración glomerular levemente disminuida

Filtración glomerular moderadamente

disminuida

Filtración glomerular
gravemente disminuida

Falla renal

Hiperfiltración

Reserva de la función renal

Albuminuria y proteinuria

Albuminuria

Concentración de

albúmina en orina

Tasa de excreción de albúmina en orina

Relación albuminuria/ creatininuria

Proteinuria

Concentración de proteínas en orina

Tasa de excreción de proteínas en orina

Relación proteinuria/ creatininuria

\section{Abreviaturas Fundamento/explicación} sugeridas $^{\mathrm{a}}$

$\mathrm{ACle}_{\text {cr }}$

Estimación del aclaramiento con uso de la creatinina

Se usa para describir el estadio de FG independientemente de la presencia 0 ausencia de enfermedad renal; las unidades para la FG son $\mathrm{ml} / \mathrm{min}$ por $1.73 \mathrm{~m}^{2} 0 \mathrm{ml} / \mathrm{min}$; pueden agregarse varias categorías (p. ej., G3-G5)

G1

$\mathrm{FG} \geq 90 \mathrm{ml} / \mathrm{min}$ por $1.73 \mathrm{~m}^{2}$

G2

FG $60-89 \mathrm{ml} / \mathrm{min}$ por $1.73 \mathrm{~m}^{2}$

G3a

G4

FG $30-44 \mathrm{ml} / \mathrm{min}$ por $1.73 \mathrm{~m}^{2}$

FG $15-29 \mathrm{ml} / \mathrm{min}$ por $1.73 \mathrm{~m}^{2}$

G5

FG $<15 \mathrm{ml} / \mathrm{min}$ por $1.73 \mathrm{~m}^{2} \mathrm{o}$ en tratamiento con diálisis

En general se acepta el término de hiperfiltración; sin embargo no está claramente definido. Si este término se utiliza como exposición, desenlace o covariante, se debe definir la FG (p. ej., > $120 \mathrm{ml} / \mathrm{min}$ por $1.73 \mathrm{~m}^{2}$ )

El concepto de reserva de FG se define generalmente como la diferencia entre la FG estimulada y el basal

Especificar las condiciones de medición (muestras puntuales o temporizadas; cuantitativas o tira reactiva); diferenciar las proteínas diferentes de la albúmina según esté clínicamente indicado

AlbU

Requiere recolección de orina cronometrada; el intervalo para la recolección de orina debe constar por separado en "métodos"; la unidad de tiempo puede variar (horas-días)

I $\mathrm{Alb}_{\mathrm{U}} /$ Creat $_{U} \quad$ Por recolección de orina cronometrada o recolección de orina puntual; el intervalo para la recolección de orina cronometrada o la hora del día para la recolección de orina puntual debe constar por separado en "métodos"

Proteinuria clínica, proteinuria manifiesta

$\operatorname{Prot}_{u}$

Requiere recolección de orina cronometrada; el intervalo para la recolección de orina debe constar por separado en "métodos"; la unidad de tiempo puede variar (horas-días)

I Prot ${ }_{U} /$ Creat $_{U} \quad$ Por recolección de orina cronometrada o recolección de orina puntual; el intervalo para la recolección de orina cronometrada o la hora del día para la recolección de orina puntual deben constar por separado en "métodos"
Microalbuminuria,

macroalbuminuria

Términos a evitar

Terminos a evitar

(1)


Tabla 5. Indicadores de la función renal (Continuación)

\begin{tabular}{|c|c|c|c|}
\hline Término preferido & $\begin{array}{l}\text { Abreviaturas } \\
\text { sugeridas }^{\mathrm{a}}\end{array}$ & Fundamento/explicación & Términos a evitar \\
\hline $\begin{array}{l}\text { Categorías de } \\
\text { albuminuria y proteinuria }\end{array}$ & & $\begin{array}{l}\text { Para utilizar en la descripción del valor de albuminuria o } \\
\text { proteinuria independientemente de la presencia o ausencia } \\
\text { de enfermedad renal }\end{array}$ & \\
\hline Normal & & $\mathrm{Alb}_{\mathrm{u}}<10 \mathrm{mg} / \mathrm{día} ; \mathrm{I} \mathrm{Alb}_{\mathrm{U}} /$ Creat $_{\mathrm{u}}<10 \mathrm{mg} / \mathrm{g}(<1 \mathrm{mg} / \mathrm{mmol})$ & Normoalbuminuria \\
\hline Levemente aumentada & & Alb $_{u} 10-29 \mathrm{mg} /$ día; I Alb $/$ Creat $_{u} 10-29 \mathrm{mg} / \mathrm{g}(1.0-2.9 \mathrm{mg} / \mathrm{mmol})$ & \\
\hline $\begin{array}{l}\text { Normal a levemente } \\
\text { aumentada }\end{array}$ & A1 & $\begin{array}{l}\text { Alb }_{U}<30 \mathrm{mg} / \mathrm{dí}^{\prime} ; \text { I Alb } \\
\text { Prot }_{U}<150 \mathrm{mg} / \text { Creat }_{\mathrm{U}}<30 \mathrm{mg} / \mathrm{g}(<3 \mathrm{mg} / \mathrm{mmol}) \\
\text { Prot }_{U} / \text { Creat }_{U}<150 \mathrm{mg} / \mathrm{g}(<15 \mathrm{mg} / \mathrm{mmol})\end{array}$ & \\
\hline \multirow{2}{*}{$\begin{array}{l}\text { Moderadamente } \\
\text { aumentada }\end{array}$} & \multirow[t]{2}{*}{ A2 } & Alb $_{u} 30-300$ mg/día; I Alb $/$ Creat $_{u} 30-300$ mg/g (3-30 mg/mmol) & \multirow[t]{2}{*}{ Microalbuminuria } \\
\hline & & $\begin{array}{l}\text { Prot }_{u} 50-500 \mathrm{mg} / \mathrm{dí} ; \text {; I Prot } \\
\left.\text { (15-50 } / \text { Creat }_{\mathrm{u}} 150-500 \mathrm{mg} / \mathrm{mmol}\right)\end{array}$ & \\
\hline Gravemente aumentada & A3 & $\begin{array}{l}\text { Alb }_{U}>300 \mathrm{mg} / \text { día; I Alb }_{U} / \text { Creat }_{U}>300 \mathrm{mg} / \mathrm{g} \text { (>30 mg/mmol) Prot } \\
>500 \mathrm{mg} / \mathrm{día} \text {; I Prot } / \text { Preat }_{u}>500 \mathrm{mg} / \mathrm{g}(>50 \mathrm{mg} / \mathrm{mmol})\end{array}$ & $\begin{array}{l}\text { Macroalbuminuria, } \\
\text { proteinuria clínica, } \\
\text { proteinuria manifiesta }\end{array}$ \\
\hline Síndrome nefrótico ${ }^{d}$ & & $\begin{array}{l}\text { Alb }_{U}>2,200 \mathrm{mg} / \mathrm{día} \text {; I } \mathrm{Alb}_{\mathrm{U}} / \mathrm{Creat}_{\mathrm{U}}>2,200 \mathrm{mg} / \mathrm{g} \text { ( }>220 \mathrm{mg} / \mathrm{mmol} \text { ) } \\
\left.\text { Prot }_{\mathrm{U}}>3,500 \mathrm{mg} / \mathrm{día} \text {; I Prot } / \text { Creat }_{U}>3,500 \mathrm{mg} / \mathrm{g} \text { ( }>350 \mathrm{mg} / \mathrm{mmol}\right) \\
\text { Especificar si es con o sin síndrome nefrótico, como lo señala } \\
\text { la presencia de hipoalbuminemia (con edema e hiperlipidemia } \\
\text { en la mayor parte de los casos) }\end{array}$ & \\
\hline $\begin{array}{l}\text { Función tubular Secreción } \\
\text { tubular }\end{array}$ & ST & $\begin{array}{l}\text { Se requieren especificaciones + A138 adicionales para } \\
\text { distinguir la velocidad, la fracción libre o excretada (en } \\
\text { comparación con la carga filtrada) }\end{array}$ & \\
\hline Reabsorción tubular & RT & $\begin{array}{l}\text { Se requieren especificaciones adicionales para distinguir la } \\
\text { velocidad, la fracción libre o excretada (en comparación con } \\
\text { la carga filtrada) }\end{array}$ & \\
\hline $\begin{array}{l}\text { Marcador de la fracción } \\
\text { de excreción }\end{array}$ & FENa & FE de sodio & \\
\hline $\begin{array}{l}\text { Marcador de la fracción } \\
\text { de reabsorción (no se } \\
\text { usa) }\end{array}$ & FRNa & FR de sodio & \\
\hline
\end{tabular}

AKIN: Acute Kidney Injury Network; CAC: cociente albúmina-creatinina; CKD-EPI: CKD Epidemiology Collaboration; CPC: cociente proteína-creatinina; Crs: creatinina sérica; DP: diálisis peritoneal; DRA: disfunción renal aguda; ERC: enfermedad renal crónica; ERCA: enfermedad renal crónica avanzada; ERC-ND: ERC sin diálisis; ERCT: enfermedad renal crónica terminal; FENa: fracción de excreción de sodio; FG: filtración glomerular; FGe: filtración glomerular estimada; FRNa: fracción de reabsorción de sodio; HD: hemodiálisis; HDF: hemodiafiltración; HF: hemofiltración; IR: insuficiencia renal; IRA insuficiencia renal aguda; KDIGO: Kidney Disease: Improving Global Outcomes; LRA, lesión renal aguda; MDRD: Modification of Diet in Renal Disease Study, FGm: FG medida; RIFLE: Risk, Injury, Failure, Loss, End-stage renal failure; RT: reabsorción tubular; ST, secreción tubular; TRS, tratamiento renal sustitutivo.

a El estilo de la revista dictará la necesidad de abreviar los términos.

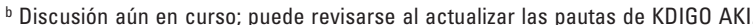

${ }^{c}$ Discusión aún en curso; podría revisarse en la conferencia de consenso KDIGO AKD.

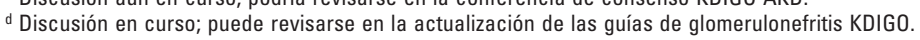

Tabla 1. Função e doença renal

\begin{tabular}{|l|l|l|l|}
\hline Termo preferível & $\begin{array}{l}\text { Abreviação } \\
\text { sugerida }\end{array}$ & Razão/Explicação & Termos a evitar \\
\hline $\begin{array}{l}\text { Parte 1. Função renal } \\
\text { e doença renal }\end{array}$ & & $\begin{array}{l}\mathbf{0} \text { termo "renal" deve ser preferencialmente } \\
\text { utilizado na descrição de doenças ou aspectos } \\
\text { funcionais dos rins, com algumas exceções }\end{array}$ & $\begin{array}{l}\text { O prefixo "nefro-" (exceto no } \\
\text { contexto de síndromes, doenças ou } \\
\text { funções específicas, veja abaixo) }\end{array}$ \\
\hline Doença renal & $\begin{array}{l}\text { Reflete o conjunto de doenças agudas e crónicas } \\
\text { do rim }\end{array}$ & $\begin{array}{l}\text { Nefropatia (exceto no } \\
\text { enquadramento de doenças } \\
\text { específicas, ex., nefropatia } \\
\text { membranosa) }\end{array}$ \\
\hline
\end{tabular}


Nefro Latinoam. 2020;17

Tabla 1. Função e doença renal (Continuación)

\begin{tabular}{|c|c|c|c|}
\hline Termo preferível & $\begin{array}{l}\text { Abreviação } \\
\text { sugerida }^{\mathrm{a}}\end{array}$ & Razão/Explicação & Termos a evitar \\
\hline Função renal & & $\begin{array}{l}\text { Reflete o conjunto complexo e diferente de funções } \\
\text { fisiológicas do rim; Não deve ser igualado apenas à } \\
\text { taxa de filtração glomerular (TFG) }\end{array}$ & $\mathrm{N} / \mathrm{A}$ \\
\hline Função renal normal & & $\begin{array}{l}\text { Termo geral aplicável a vários aspetos da função } \\
\text { renal, que devem ser especificados }\end{array}$ & $\mathrm{N} / \mathrm{A}$ \\
\hline Função renal alterada & & $\begin{array}{l}\text { Termo geral aplicável a vários aspetos da função } \\
\text { renal e devem ser especificados }\end{array}$ & $\begin{array}{l}\text { Deficiência renal, insuficiência, } \\
\text { dano, disfunção; azotemia }\end{array}$ \\
\hline $\begin{array}{l}\text { Função renal residual } \\
\text { (FRR) }\end{array}$ & FRR & $\begin{array}{l}\text { Função renal em pessoas com insuficiência renal } \\
\text { que recebem TRS; são necessárias especificações } \\
\text { adicionais, por exemplo, taxa de fluxo de urina, } \\
\text { depuração do soluto. Embora seja geralmente } \\
\text { usado no cenário da diálise, esse termo pode ser } \\
\text { usado para se referir à função renal de rins nativos } \\
\text { em receptores de transplante renal. }\end{array}$ & NA \\
\hline Estrutura renal & & $\begin{array}{l}\text { Reflete a totalidade das estruturas diferentes e } \\
\text { complexas do rim, verificadas por imagens e } \\
\text { marcadores de injúria ou lesão }\end{array}$ & NA \\
\hline Estrutura renal normal & & $\begin{array}{l}\text { Termo geral aplicável a vários aspectos da estrutura } \\
\text { renal, que deve ser especificado }\end{array}$ & NA \\
\hline $\begin{array}{l}\text { Estrutura renal } \\
\text { alterada }\end{array}$ & & $\begin{array}{l}\text { Termo geral aplicável a vários aspectos da estrutura } \\
\text { renal, que deve ser especificado }\end{array}$ & NA \\
\hline Causa de doença renal & & $\begin{array}{l}\text { A causa de IRA/LRA, DRA e DRC deve ser indicada } \\
\text { sempre que possível. A causa pode ser conhecida, } \\
\text { presumida ou desconhecida. Deve-se especificar o } \\
\text { método empregado para investigação e atribuição } \\
\text { da causa. }\end{array}$ & $\begin{array}{l}\text { A causa não deve ser inferida } \\
\text { apenas pela presença de uma } \\
\text { condição comórbida (como diabetes) }\end{array}$ \\
\hline
\end{tabular}

Tabla 2. Falência renal

\begin{tabular}{|c|c|c|c|}
\hline Termo preferível & $\begin{array}{l}\text { Abreviação } \\
\text { sugerida }^{\mathrm{a}}\end{array}$ & Razão/Explicação & Termos a evitar \\
\hline $\begin{array}{l}\text { Parte 2. Falência } \\
\text { renal }\end{array}$ & & $\begin{array}{l}\text { Terapia renal substitutiva (tratamento dialítico ou } \\
\text { transplante) }\end{array}$ & $\begin{array}{l}\text { Doença renal em estágio terminal } \\
\text { (DRT); doença renal em estágio } \\
\text { terminal (DRCT), nefropatia; } \\
\text { enfraquecimento/insuficiência/ } \\
\text { disfunção renal; azotemia }\end{array}$ \\
\hline Duração & & Especificação necessária & \\
\hline $\begin{array}{l}\text { Injúria (termo } \\
\text { recomendado no } \\
\text { Brasil) ou lesão } \\
\text { (única opção em } \\
\text { Portugal) renal } \\
\text { aguda estágio } 3^{\text {b }}\end{array}$ & $\begin{array}{l}\text { IRA (Brasil) / LRA } \\
\text { (Portugal) } \\
\text { estágio } 3\end{array}$ & Duração da doença $\leq 3$ meses & $\begin{array}{l}\text { nefropatia; enfraquecimento/ } \\
\text { insuficiência/disfunção renal; } \\
\text { azotemia; uremia }\end{array}$ \\
\hline Falência renal & FR & Duração da doença $>3$ meses & $\begin{array}{l}\text { Nefropatia crônica/crónica; } \\
\text { enfraquecimento/insuficiência/ } \\
\text { disfunção renal; azotemia; uremia; } \\
\text { insuficiência renal irreversível }\end{array}$ \\
\hline Sinais e sintomas & & $\begin{array}{l}\text { Especificação necessária (com sintomas e sinais, } \\
\text { sem os mesmos ou sem-informação); quando com } \\
\text { sinais e sintomas seria sinônimo (Brasil)/sinónimo } \\
\text { (Portugal) de uremia }\end{array}$ & NA \\
\hline $\begin{array}{l}\text { Uremia/síndrome } \\
\text { urêmica }\end{array}$ & & $\begin{array}{l}\text { Síndrome que consiste de sintomas e sinais associados } \\
\text { à falência renal (não indica um papel causal da ureia) }\end{array}$ & NA \\
\hline Tratamento & & Especificação necessária & NA \\
\hline
\end{tabular}


Tabla 2. Falência renal (Continuación)

\begin{tabular}{|c|c|c|c|}
\hline Termo preferível & $\begin{array}{l}\text { Abreviação } \\
\text { sugerida }^{\mathrm{a}}\end{array}$ & Razão/Explicação & Termos a evitar \\
\hline $\begin{array}{l}\text { Terapia renal } \\
\text { substitutiva }^{c}\end{array}$ & TRS & $\begin{array}{l}\text { É necessária uma especificação adicional, como } \\
\text { diálise e transplante }\end{array}$ & NA \\
\hline \multirow[t]{2}{*}{ Diálise } & $\frac{\underline{\operatorname{IRA} / \text { LRA }}}{\underline{\text { estágio } 3 \mathrm{D}}}$ & IRA/LRA estágio 3 tratada por diálise & IRA-D, IRA dependente de diálise \\
\hline & DRC E5D & DRC E5 tratada por diálise & $\begin{array}{l}\text { DRCT, DRT, FRT, DRC dependente de } \\
\text { diálise }\end{array}$ \\
\hline Duração & & $\begin{array}{l}\text { Longo prazo vs. curto prazo: longo prazo refere-se } \\
\text { à diálise para DRC (também pode ser chamada de } \\
\text { diálise de manutenção); curto prazo refere-se à } \\
\text { diálise para DRA }\end{array}$ & $\begin{array}{l}\text { Diálise crônica/crónica, diálise } \\
\text { aguda (os termos agudo e crônico } \\
\text { referem-se à duração da doença } \\
\text { renal em vez da duração do } \\
\text { tratamento dialítico) }\end{array}$ \\
\hline $\begin{array}{l}\text { Modalidade e } \\
\text { frequência }\end{array}$ & & Modalidades & NA \\
\hline Transplantação renal & & hemodiálise (HD) & \\
\hline Origem do dador & & hemofiltração (HF) & \\
\hline $\begin{array}{l}\text { Falência renal com } \\
\text { terapêutica de } \\
\text { substituição }\end{array}$ & & hemodiafiltração (HDF) & \\
\hline $\begin{array}{l}\text { Falência renal sem } \\
\text { terapêutica de } \\
\text { substituição }\end{array}$ & & $\begin{array}{l}\text { diálise peritoneal (DP, ambulatorial ou } \\
\text { automatizada) }\end{array}$ & \\
\hline $\begin{array}{l}\text { Com terapêutica } \\
\text { conservadora } \\
\text { compreensiva }\end{array}$ & & Frequência & \\
\hline $\begin{array}{l}\text { Sem terapêutica } \\
\text { conservadora } \\
\text { compreensiva }\end{array}$ & & contínua & \\
\hline
\end{tabular}

Tabla 3. Doenças e patologias renais agudas (DRA) e lesão renal aguda (LRA)

\begin{tabular}{|c|c|c|c|}
\hline Termo preferível & $\begin{array}{l}\text { Abreviação } \\
\text { sugerida }^{a}\end{array}$ & Razão/Explicação & Termos a evitar \\
\hline $\begin{array}{l}\text { Part 3. Desordens e } \\
\text { doenças renais } \\
\text { agudas (DRA) e } \\
\text { injúria/lesão renal } \\
\text { aguda (IRA/LRA) }\end{array}$ & & $\begin{array}{l}\text { Duração da doença } \leq 3 \text { meses; conceitualmente diferente } \\
\text { do diagnóstico inicial da DRC }\end{array}$ & Insuficiência renal aguda \\
\hline $\begin{array}{l}\text { Doenças renais } \\
\text { agudas }\end{array}$ & $\mathrm{DRA}^{\mathrm{c}}$ & $\begin{array}{l}\text { Definição do KDIGO: IRA/LRA, ou TFG }<60 \mathrm{ml} / \text { min por 1,73 } \\
\mathrm{m}^{2} \text {, ou marcadores de injúria renal por } \leq 3 \text { meses, ou } \\
\text { diminuição da TFG em } \geq 35 \% \text { ou aumento da creatinina } \\
\text { sérica em }>50 \% \text { por } \leq 3 \text { meses }\end{array}$ & $\mathrm{N} / \mathrm{A}$ \\
\hline $\begin{array}{l}\text { Injuria/lesão renal } \\
\text { aguda }\end{array}$ & IRA/LRA & $\begin{array}{l}\text { Definição do KDIGO (IRA/LRA é uma subcategoria de DRA): } \\
\text { oligúria por }>6 \mathrm{~h} \text {, elevação da Crs }>0,3 \mathrm{mg} / \mathrm{dl} \text { em } 2 \mathrm{~d} \\
\text { ou }>50 \% \text { em } 1 \text { semana }\end{array}$ & \\
\hline $\begin{array}{l}\text { Classificação da } \\
\text { IRA/LRA }\end{array}$ & & $\begin{array}{l}\text { Classificação do KDIGO por causa e estágio é } \\
\text { recomendada, em vez de estágio isolado; por exemplo, um } \\
\text { paciente com IRA estágio } 3 \text { devido a NTA; a classificação } \\
\text { se aplica a todos os estágios de IRA/LRA }\end{array}$ & $\begin{array}{l}\text { Classificações anteriores, } \\
\text { incluindo RIFLE e AKIN } \\
\text { (a classificação KDIGO } \\
\text { harmonizou essas definições } \\
\text { anteriores) }\end{array}$ \\
\hline \multirow[t]{3}{*}{ Estágios da IRA/LRA } & $\begin{array}{l}\text { IRA/LRA } \\
\text { estágio } 1\end{array}$ & Critérios da creatinina sérica e / ou do volume urinário & $\mathrm{N} / \mathrm{A}$ \\
\hline & $\begin{array}{l}\text { IRA/LRA } \\
\text { estágio } 2\end{array}$ & Critérios da creatinina sérica e / ou do volume urinário & N/A \\
\hline & $\begin{array}{l}\text { IRA/LRA } \\
\text { estágio } 3\end{array}$ & Critérios da creatinina sérica e / ou do volume urinário & $\mathrm{N} / \mathrm{A}$ \\
\hline
\end{tabular}


Tabla 4. Doença renal crónica (DRC)

\begin{tabular}{|c|c|c|c|}
\hline Termo preferível & $\begin{array}{l}\text { Abreviação } \\
\text { sugerida }^{\mathrm{a}}\end{array}$ & Razão/Explicação & Termos a evitar \\
\hline $\begin{array}{l}\text { Part 4. Doença renal } \\
\text { crônica/crónica (DRC) }\end{array}$ & & Duração da doença> 3 meses & $\begin{array}{l}\text { DRCT; enfraquecimento renal, } \\
\text { insuficiência, disfunção; azotemia }\end{array}$ \\
\hline DRC & & $\begin{array}{l}\text { Definição do KDIGO: TFG }<60 \mathrm{ml} / \min \text { por } 1,73 \mathrm{~m}^{2} \\
\text { ou marcadores de injúria renal por }>3 \text { meses }\end{array}$ & $\begin{array}{l}\text { DRCT; deficiência renal, } \\
\text { insuficiência, disfunção; azotemia }\end{array}$ \\
\hline Classificação da DRC & & $\begin{array}{l}\text { Classificação CEA do KDIG0 por causa, estágio (E1 } \\
\text { - E5) e faixa da albuminúria (A1 - A3) - veja abaixo } \\
\text { as definições das categorias E e A. Por exemplo, } \\
\text { um paciente com DRC E1, A3 devido a diabetes ou } \\
\text { uma coorte com DRC E4 - E5, A1 - A3 de qualquer } \\
\text { causa. Observe que a classificação da DRC é } \\
\text { aplicável apenas a pessoas com DRC. Portanto, se } \\
\text { não houver outra evidência de injúria renal, um } \\
\text { paciente não poderia ser classificado como "DRC } \\
\text { E2, A1". }\end{array}$ & $\begin{array}{l}\text { DRC leve, moderada, grave, } \\
\text { precoce; DRC estágio 1-5 } \\
\text { (descrição completa preferida ao } \\
\text { invés do estágio sozinho) }\end{array}$ \\
\hline DRC sem TRS & DRC sem TRS & $\begin{array}{l}\text { DRC E1 - E5, A1 - A3 de qualquer causa, sem estar } \\
\text { em diálise ou ter sido transplantado. }\end{array}$ & $\begin{array}{l}\text { DRC-ND (DRC não-dialítica), } \\
\text { DRC-NDD (DRC não-dependente } \\
\text { de diálise), DRC pré-dialítica, DRC } \\
\text { pré-DRCT }\end{array}$ \\
\hline $\begin{array}{l}\text { Categoria de risco } \\
\text { para DRC }\end{array}$ & & $\begin{array}{l}\text { Definições do KDIGO (as cores se referem ao mapa } \\
\text { de calor, Figura Suplementar S1) a menos que } \\
\text { definido de outra forma; o risco depende do } \\
\text { desfecho considerado }\end{array}$ & $\begin{array}{l}\text { DRC leve, moderada, grave, } \\
\text { precoce }\end{array}$ \\
\hline $\begin{array}{l}\text { Categoria de risco } \\
\text { para DRC -baixo }\end{array}$ & risco baixo & Refere-se a E1A1, E2A1 (verde) & NA \\
\hline $\begin{array}{l}\text { Categoria de risco } \\
\text { para DRC } \\
\text {-moderadamente alto }\end{array}$ & risco moderado & Refere-se a E1A2, E2A2, E3aA1 (amarelo) & NA \\
\hline $\begin{array}{l}\text { Categoria de risco } \\
\text { para DRC - alto }\end{array}$ & risco alto & Refere-se a E1A3, E2A3, E3aA2, E3bA1 (Iaranja) & NA \\
\hline $\begin{array}{l}\text { Categoria de risco } \\
\text { para DRC -muito alto }\end{array}$ & risco muito alto & $\begin{array}{l}\text { Refere-se a E3aA3, E3bA2, E3bA3, E4A1, E4A2, } \\
\text { E4A3, E5A1, E5A2, E5A3 (vermelho) }\end{array}$ & NA \\
\hline \multirow[t]{2}{*}{ Progressão da DRC } & & $\begin{array}{l}\text { Refere-se ao declínio da TFG ou agravamento da } \\
\text { albuminúria. Outros biomarcadores não estão } \\
\text { incluídos. Ainda não há consenso sobre o uso de } \\
\text { termos específicos para descrever a cronologia } \\
\text { (por exemplo, precoce, tardio) ou a taxa da } \\
\text { progressão (rápida, lenta). O uso de termos } \\
\text { específicos deve ser definido nos métodos. }\end{array}$ & NA \\
\hline & & $\begin{array}{l}\text { Outras especificações podem ser necessárias: } \\
\text { pode ocorrer declínio da TFG durante tratamento } \\
\text { para outras condições, que podem não ser } \\
\text { consideradas como progressão da DRC. }\end{array}$ & \\
\hline Remissão da DRC & & $\begin{array}{l}\text { Refere-se à melhora da TFG ou da albuminúria. Os } \\
\text { critérios dependem da doença. } 0 \text { uso de termos } \\
\text { específicos deve ser definido nos métodos. }\end{array}$ & NA \\
\hline
\end{tabular}


Tabla 5. Medidas renais (Continuación)

\begin{tabular}{|c|c|c|c|}
\hline Termo preferível & $\begin{array}{l}\text { Abreviação } \\
\text { sugerida }^{\mathrm{a}}\end{array}$ & Razão/Explicação & Termos a evitar \\
\hline $\begin{array}{l}\text { Parte 5. Avaliações } \\
\text { renais }\end{array}$ & & $\begin{array}{l}\text { Aplica-se a pessoas com ou sem doença renal; considere } \\
\text { problemas de aferição (métodos) e variabilidade (várias } \\
\text { medidas podem melhorar a classificação). }\end{array}$ & N/A \\
\hline $\begin{array}{l}\text { Taxa de filtração } \\
\text { glomerular e } \\
\text { depuração }\end{array}$ & & $\begin{array}{l}\text { TFG e depuração da creatinina não são sinônimos/ } \\
\text { sinónimos }\end{array}$ & NA \\
\hline $\begin{array}{l}\text { Taxa de filtração } \\
\text { glomerular }\end{array}$ & TFG & $\begin{array}{l}\text { As unidades devem ser especificadas ( } \mathrm{ml} / \mathrm{min} \text { por } 1,73 \mathrm{~m}^{2} \\
\text { ou } \mathrm{ml} / \mathrm{min} \text { ) }\end{array}$ & NA \\
\hline $\begin{array}{l}\text { Taxa de filtração } \\
\text { glomerular medida }\end{array}$ & TFGm & $\begin{array}{l}\text { Os métodos de depuração e marcadores de filtração } \\
\text { exógenos devem ser anotados separadamente nos métodos }\end{array}$ & NA \\
\hline $\begin{array}{l}\text { Taxa de filtração } \\
\text { glomerular estimada }\end{array}$ & TFGe & $\begin{array}{l}\text { As equações de estimativa (por exemplo, CKD-EPI e MDRD) e } \\
\text { marcadores de filtração (por exemplo, creatinina e cistatina } \\
\text { C) devem ser anotados separadamente nos métodos }\end{array}$ & NA \\
\hline \multirow{2}{*}{$\begin{array}{l}\text { Taxa de filtração } \\
\text { glomerular estimada; } \\
\text { marcador }\end{array}$} & $\mathrm{TFGe}_{\mathrm{cr}}$ & TFGe usando creatinina/ TFGe usando cistatina C & \multirow[t]{2}{*}{ NA } \\
\hline & $\begin{array}{l}\mathrm{TFGe}_{\text {cys }} \\
\mathrm{TFGe}_{\text {cr-cys }}\end{array}$ & TFGe usando creatinina e cistatina $C$ & \\
\hline Depuração & Dep & $\begin{array}{l}0 \text { soluto deve ser especificado; as unidades devem ser } \\
\text { especificadas ( } \mathrm{ml} / \mathrm{min} \text { por } 1,73 \mathrm{~m}^{2} \text { ou } \mathrm{ml} / \mathrm{min} \text { ) }\end{array}$ & NA \\
\hline Depuração medida & Dep-m & $\begin{array}{l}\text { Os métodos e marcadores de depuração devem ser } \\
\text { anotados separadamente nos métodos }\end{array}$ & NA \\
\hline $\begin{array}{l}\text { Depuração medida; } \\
\text { marcador }\end{array}$ & $\begin{array}{l}\text { Dep-mur } \\
\text { Dep-mcr } \\
\text { Dep-mur-cr }\end{array}$ & $\begin{array}{l}\text { Dep-m usando ureia; Dep-m usando creatinina; Dep-m } \\
\text { usando ureia e creatinina }\end{array}$ & N/A \\
\hline Depuração estimada & Dep-e & $\begin{array}{l}\text { As equações de estimativa (por exemplo, Cockcroft-Gault) e } \\
\text { marcadores devem ser anotados separadamente nos } \\
\text { métodos }\end{array}$ & NA \\
\hline $\begin{array}{l}\text { Depuração estimada; } \\
\text { marcador }\end{array}$ & Dep-e ${ }_{\text {cr }}$ & Dep-e usando creatinina & NA \\
\hline Categorias da TFG & & $\begin{array}{l}\text { Para uso na descrição do nível de TFG, independentemente } \\
\text { da presença ou ausência de doença renal; as unidades de } \\
\text { TFG são ml / min por } 1,73 \mathrm{~m}^{2} \text { para essas categorias; várias } \\
\text { categorias podem ser agrupadas (por exemplo, E3-E5) }\end{array}$ & NA \\
\hline $\begin{array}{l}\text { TFG normal a } \\
\text { aumentada }\end{array}$ & E1 & TFG $\geq 90 \mathrm{ml} / \min$ por $1,73 \mathrm{~m}^{2}$ & NA \\
\hline $\begin{array}{l}\text { TFG com redução } \\
\text { discreta }\end{array}$ & E2 & TFG $60-89 \mathrm{ml} / \mathrm{min}$ por $1,73 \mathrm{~m}^{2}$ & NA \\
\hline $\begin{array}{l}\text { TFG com redução } \\
\text { moderada }\end{array}$ & E3aE3b & TFG $45-59 \mathrm{ml} / \mathrm{min}$ por $1,73 \mathrm{~m}^{2}$ & NA \\
\hline $\begin{array}{l}\text { TFG com redução } \\
\text { acentuada }\end{array}$ & E4 & TFG $15-29 \mathrm{ml} / \mathrm{min}$ por $1,73 \mathrm{~m}^{2}$ & NA \\
\hline $\begin{array}{l}\text { Doença renal } \\
\text { avançada }\end{array}$ & E5c & TFG $<15 \mathrm{ml} / \min$ por $1,73 \mathrm{~m}^{2}$ sem TRS & NA \\
\hline Falência renal & $\mathrm{E5}_{\text {TRS }}$ & $\begin{array}{l}\text { Terapia renal substitutiva (tratamento dialítico ou } \\
\text { transplante) }\end{array}$ & NA \\
\hline
\end{tabular}


Nefro Latinoam. 2020;17

Tabla 5. Medidas renais (Continuación)

\begin{tabular}{|c|c|c|}
\hline Termo preferível & $\begin{array}{l}\text { Abreviação } \\
\text { sugerida }^{\mathrm{a}}\end{array}$ & Razão/Explicação \\
\hline Hiperfiltração & & $\begin{array}{l}0 \text { conceito de hiperfiltração é geralmente aceito (Brasil)/ } \\
\text { aceite (Portugal), mas não definido de forma consistente. S } \\
\text { esse termo for usado como exposição, desfecho ou } \\
\text { covariável, o limite de TFG deve ser definido (por exemplo, } \\
>120 \mathrm{ml} / \text { min por } 1,73 \mathrm{~m}^{2} \text { ). }\end{array}$ \\
\hline Reserva da TFG & & $\begin{array}{l}0 \text { conceito de reserva de TFG é geralmente aceito/aceite } \\
\text { como a diferença entre TFG estimulada e basal }\end{array}$ \\
\hline $\begin{array}{l}\text { Albuminúria e } \\
\text { proteinúria }\end{array}$ & & $\begin{array}{l}\text { Especifique as condições de medição (amostras isoladas } \\
\text { versus cronometradas; quantitativa versus fita reagente); } \\
\text { diferenciar proteínas outras que não a albumina, conforme } \\
\text { indicado clinicamente }\end{array}$ \\
\hline
\end{tabular}

\section{Albuminúria}

TEA

Concentração

urinária de albumina

Requer coleta de urina cronometrada; o intervalo para coleta de urina deve ser anotado separadamente nos

Taxa de excreção urinária de albumina

Relação albumina-

RAC métodos; unidade de tempo pode variar (h ou d)

NA

NA

NA creatinina na urina

Refere-se à coleta de urina cronometrada ou amostra isolada; o intervalo para coleta de urina cronometrada ou a hora do dia para coleta da amostra isolada, devem ser anotados separadamente nos métodos

\section{Proteinúria}

Concentração

Requer coleta de urina cronometrada; o intervalo para coleta de urina deve ser anotado separadamente nos métodos; unidade de tempo pode variar (h ou d)

Taxa de excreção urinária de proteína

Relação proteína-

Refere-se à coleta de urina cronometrada ou amostra creatinina na urina

isolada; o intervalo para coleta de urina cronometrada ou a hora do dia para coleta da amostra isolada, devem ser anotados separadamente nos métodos

\section{Categorias de albuminúria e proteinúria}

Normal

Discretamente elevada (discreta)

Normal a

Para uso na descrição do nível de albuminúria ou proteinúria, independentemente da presença ou ausência de doença renal

TEA $<10 \mathrm{mg} / \mathrm{d} ; \mathrm{RAC}<10 \mathrm{mg} / \mathrm{g}$ ( $<1 \mathrm{mg} / \mathrm{mmol})$

TEA $10-29 \mathrm{mg} / \mathrm{d}$; RAC $10-29 \mathrm{mg} / \mathrm{g}(1,0-2,9 \mathrm{mg} / \mathrm{mmol})$

discretamente

elevada (normal a

discreta)

Moderadamente

aumentado

(moderado)

Moderadamente NA

NA

Normoalbuminúria

Microalbuminúria, macroalbuminúria

NA

Proteinuria clínica, proteinúria declarada

NA

Macroalbuminuria, proteinuria clínica, proteinuria manifiesta

Microalbuminúria 
Tabla 5. Medidas renais (Continuación)

\begin{tabular}{|c|c|c|c|}
\hline Termo preferível & $\begin{array}{l}\text { Abreviação } \\
\text { sugerida }^{\mathrm{a}}\end{array}$ & Razão/Explicação & Termos a evitar \\
\hline severa & A3 & $\begin{array}{l}\text { TEA }>300 \mathrm{mg} / \mathrm{d} ; \mathrm{RAC}>300 \mathrm{mg} / \mathrm{g}(>30 \mathrm{mg} / \mathrm{mmol}) \mathrm{TEP}> \\
500 \mathrm{mg} / \mathrm{d} ; \mathrm{RPC}>500 \mathrm{mg} / \mathrm{g}(>50 \mathrm{mg} / \mathrm{mmol})\end{array}$ & $\begin{array}{l}\text { Macroalbuminúria, } \\
\text { proteinúria clínica, } \\
\text { proteinúria declarada }\end{array}$ \\
\hline \multirow{3}{*}{$\begin{array}{l}\text { Faixa nefrótica / } \\
\text { síndrome }^{d}\end{array}$} & & TEA $>2200 \mathrm{mg} / \mathrm{d} ; \mathrm{RAC}>2200 \mathrm{mg} / \mathrm{g}$ (> $220 \mathrm{mg} / \mathrm{mmol})$ & \multirow[t]{3}{*}{ NA } \\
\hline & & $\mathrm{TEP}>3500 \mathrm{mg} / \mathrm{d} ; \mathrm{RPC}>3500 \mathrm{mg} / \mathrm{g}(>350 \mathrm{mg} / \mathrm{mmol})$ & \\
\hline & & $\begin{array}{l}\text { Especificar com ou sem síndrome nefrótica, como } \\
\text { observado pela presença de hipoalbuminemia (com edema } \\
\text { e hiperlipidemia na maioria dos casos) }\end{array}$ & \\
\hline $\begin{array}{l}\text { Função tubular/ } \\
\text { secreção tubular }\end{array}$ & ST & $\begin{array}{l}\text { É necessária uma especificação adicional para distinguir } \\
\text { taxa, depuração ou fração (em comparação com a carga } \\
\text { filtrada) }\end{array}$ & \\
\hline Reabsorção tubular & RT & $\begin{array}{l}\text { É necessária uma especificação adicional para distinguir } \\
\text { taxa, depuração ou fração (em comparação com a carga } \\
\text { filtrada) }\end{array}$ & NA \\
\hline $\begin{array}{l}\text { Fração de excreção, } \\
\text { marcador }\end{array}$ & $\mathrm{FE}_{\mathrm{Na}}$ & FE de sódio & \\
\hline $\begin{array}{l}\text { Fração de } \\
\text { reabsorção, } \\
\text { marcador }\end{array}$ & $\mathrm{FR}_{\mathrm{Na}}$ & FR de sódio & \\
\hline
\end{tabular}

AKIN: Acute Kidney Injury Network; CKD-EPI: CKD Epidemiology Collaboration; DP: diálise peritoneal; DRA: doença renal aguda; DRC: doença renal crónica;

DRC-ND: doença renal crónica não em diálise; DRC-NDD: doença renal crónica não dependente de diálise; EFNa: excreção fracionada de sódio; FRA: falência renal

aguda; FRT: falência renal terminal; FRTS: falência renal com terapeutica de substituição; HD: hemodiálise; HDF: hemodiafiltração; HF: hemofiltração; IRA: insuficiência renal aguda; KDIGO: Kidney Disease: Improving Global Outcomes; LRA: lesão renal aguda; MDRD: Modification of Diet in Renal Disease; mTFG: TFG medida; NTA: necrose tubular aguda; pré-DRT: pré-doença renal terminal; RAC: racio albumina creatinina; REP: racio de excreção de proteínas; RFNa: reabsorção fracionada de sódio;

RIFLE: Risk, Injury, Failure, Loss of kidney function, and End-stage kidney disease; RPC: racio proteínas creatinina; RT: reabsorção tubular; ST: secreção tubular; TEA: taxa de excreção de albumina; TFG: taxa de filtração glomerular; TRDF: transplante renal de dador falecido; TRDV: transplante renal de dador vivo; TSFR: terapeutica de substituição da função renal.

a 0 estilo da revista ditará a necessidade de abreviar os termos.

${ }^{\text {b }}$ Discussão ainda em curso; poderá ser revisto pela atualização das guidelines KDIGO AKI.

${ }^{c}$ Discussão ainda a decorrer; poderá ser revisto na conferência de consenso da KDIGO AKD.

${ }^{d}$ Discussão a decorrer; poderá ser revisto na atualização das guidelines de glomerulonefrites KDIGO 